\title{
QUEM SONHA COM DON JUAN?
}

\section{Magaly Mendes(*)}

Várias vezes citado por Lacan ao longo de seu ensino, Don Juan é aquele a quem - - de certa forma - não podemos tomar pela universal. Tal como ocorre com a mulher, que deve ser tomada uma a uma, Don Juan ganha existência na literatura através da escrita de muitos autores. Temos, portanto, a comédia de Tirso de Molina, intitulada El burlador de Servilla y el convidado de piedra, bem como o Don Juan de Cicognini, o de Perruci, o de Molière, o de Goldoni, o de Heiberg, Byron, Grabbe, Púchkin, Dumas pai, Zorrilla, Guillaume Apollinaire '... e o ideal seria tomar a cada um deles, se tivéssemos o mesmo fôlego de Don Juan, que é o de tomar a todas as mulheres, almejando por aí alcançar A Mulher.

No entanto, embora tal empreitada possa parecer encantadora, logo, logo, o irrealizável das tentativas de apreensão de um todo, sempre inapreensível, nos conduz, pela simbolização, ao inevitável da escolha.

Daí que, entre tantos Don Juan, escolhamos o primeiro deles.

Nascido não sem controvérsia - em vários de seus aspectos, quer o literário, quer ainda o que se refere ao aspecto simbólico da nomeação em Don Juan -, o âmbito da polêmica em torno de sua origem é tal que, àqueles que se perguntam quem teria gerado tão fantástico personagem, resta deparar-se com uma refinada incerteza que se estende da autoria ao próprio início do desenrolar da peça.

No que se refere às questões de autoria, a excelente introdução de Alfredo Rodrigues López-Vázquez na edição castelhana do El burlador de Servilla, publicada pela editora "Catedra Letras Hispánicas", nos esclarece vários pontos sobre a querela entre os que atribuem esta obra a Tirso de Molina e os partidários de um outro importante autor, Andrés de Claramonte. ${ }^{2}$

\footnotetext{
(*) Psiquiatra. Psicanalista.

1 LISBOA, Luiz Carlos, [s/d.], p.245.

2 MOLINA, Tirso de, 2000, p.166.
} 
Já no que diz respeito ao desenvolvimento da peça, logo no primeiro ato é o próprio Don Juan quem lança a controvérsia quanto a sua origem, quando lhe é perguntado "quem és?" "?Quién soy?". Responde ele: "Un hombre sin nombre" (MOLINA, 2000, p.11).

É assim que partindo desse anonimato, dessa tentativa de recalcamento do nome do pai, Don Juan povoa a penumbra de muitas alcovas. Qual íncubo - o demônio erótico que faz suas aparições durante o sono -, Don Juan é o sonho, ou o pesadelo, de muitos, homens ou mulheres, desde que uns e outros ocupem o lado nomeado feminino, pois como nos diz Lacan, "Don Juan é um sonho feminino" (LACAN, 1997, p.232).

É aí que o encontramos, na posição de objeto do desejo. Mas, contemporizemos, no que for possível, essa angústia. Ainda mais que o campo em que a angústia faz aparição - sendo o do enquadramento de algo que, apesar de sempre ter estado aí, de súbito surge - nos remete ao que é da ordem da cena. E, para nos colocarmos diante da cena, faz-se necessário que retrocedamos ao momento em que a angústia rapidamente se extingue pela dúvida quanto ao que surgirá se isso nos fará rir ou chorar. Esse momento que antecede a aparição da cena, é "o momento das três batidas, o momento em que se abrem as cortinas" (LACAN, 1997, p.232).

Fugaz momento, pois o que de chofre nos apresenta Tirso de Molina é, como dizia, o íncubo. As cortinas se abrem e nos deparamos com uma trama macabra onde Don Juan abandona a alcova de Isabela, a quem possuiu na escuridão, fazendo-se passar por seu pretendente Octávio. O que nos é apresentado portanto, logo de início, é da ordem do Unheimlich, de um inquietante pesadelo, que também é Esfinge. ${ }^{3}$

Tal como Esfinge, como sonho, Don Juan exige amor, e nos incita a tentar responder à demanda: decifra-me.

Como íncubo, esfinge, ou sereia, Don Juan encanta, mas não por inspirar o desejo nas mulheres, pois ele as possui tornando-se encantado, invisível, assumindo uma impostura, sempre fazendo-se passar por um outro. É por este estratagema que ele pretende burlar a Lei que rege o desejo, os limites impostos pela castração. Faz-se passar então por objeto absoluto. ${ }^{4}$ Fazendo-se passar por outro, Don

BRANDÃO, Junito de Souza, 1993, p.249.

4 LACAN, 1997, p.233. 
Juan encobre a falta, e tal como fantasma, ocupa um lugar mítico, passando assim de personagem a significante. ${ }^{5}$ Diante dele, homens ou mulheres haverão de posicionar-se.

Acompanhemos um pouco mais as aventuras desse herói, apenas lembrando antes que, se o trato por herói, é pelo fato de o herói ser aquele que, como nos diz Freud, tenta suplantar o pai. ${ }^{6}$ Voltemos então nosso olhar para a cena:

Depois de ter cometido o delito de usufruir, gozar de Isabela, Don Juan foge seguindo os conselhos de seu tio Don Pedro Tenório, que procura protegê-lo. Foge, sai de cena. Sai - como diz Lacan sobre a fuga ${ }^{7}$, partindo errante pelo mundo, numa atitude mais ou menos infantil, de sair em busca de algo que lhe é negado em todo canto. Além disto, vangloria-se: "gozoso me parto a España" (MOLINA, 2000 , p.174). Sabe-se, no entanto, que retornará à cena, onde o reencontraremos, então, naufragado.

À beira-mar, ele e seu empregado Catalinón são resgatados por uma mulher chamada Tisbea, e Don Juan - que havia desmaiado acorda nos braços desta pescadora.

Uma mulher... é o caso de ressaltar, ainda mais que quem assim se diz é a própria pescadora Tisbea, que agora abraça o mito, e este, quando desperta e pergunta onde está, ouve como resposta: “...en brazos de una mujer" (MOLINA, 2000, p.200).

Se após o naufrágio o mito reaparece, é justamente por Don Juan tomar as mulheres segundo o que, para elas, representa o sexo masculino: ele as toma uma a uma. ${ }^{8}$ Por isso é que ao ver Tisbea, Don Juan, de pronto, lhe declara seu súbito amor.

Diante dela, a declaração de amor, a letra, se faz necessária por várias causas. Citemos algumas:

Tisbea é uma mulher que sofre uma inibição denunciada em seu discurso sobre o Amor, do qual se mantém afastada e segura: "sola, de Amor exenta / como en ventura sola..." (MOLINA, 2000,

FONSECA, Letícia Patriota (org.), 1999, p.88.

FREUD, Obras completas, tomo III, 1981, p.2604.

LACAN, 1997, p.124.

8 LACAN, 1985, p.19. 
p.191). Daí decorre que Don Juan terá de argumentar para ela em favor do Amor.

Além disto, enquanto Don Juan esteve desmaiado - fora de si, como costuma-se dizer - Tisbea tem a oportunidade de obter informações sobre a identidade dele através de seu empregado Catalinón. Ela sabe, portanto, da fidalguia de Don Juan e dissimulará este saber quando ele insistir no que Lacan identifica como a essência do comportamento significante, que é o de "fazer traços falsamente falsos" (LACAN, 1997, p.72), pois Don Juan ordenará, inútil e tardiamente, a seu empregado que não revele sua identidade.

E, pela assunção de uma letra decaída, pelo sublime, Don Juan escapa do naufrágio, argumentando ainda: “...hay de mar a amar/ una letra solamente” (MOLINA, 2000, p.201).

É assim que entre declarações de amor e promessas de casamento, Don Juan consegue o assentimento de Tisbea em gozá-la: "Mucho fuego prometéis... !Plega Dios que no mintáis!" (MOLINA, 2000, p.202), roga Tisbea.

Ele mentia?

Don Juan visita Tisbea em sua "cabaña del amor" (MOLINA, 2000, p.221) - pois é assim que ela denomina sua moradia - e depois abandona-a, deixando atrás de si um rastro de fogo, no qual a cabana e o corpo de Tisbea se confundem num mesmo ardor: "! Fuego, fuego, que me quemo, / que mi cabaña se abrasa!” (MOLINA, 2000, p.223) ela grita.

Atingindo então o grau máximo da emoção e do embaraço, Tisbea tenta sair de cena. Tenta uma passagem ao ato, jogando-se ao mar. E não por acaso ao mar, pois o "mar" é, como disse Don Juan, o "amar" destituído do "a", do objeto ao qual Tisbea busca identificar-se para o Outro, lançando-se.

No entanto, neste seu movimento, é detida por Anfrisio, um dedicado admirador.

Resta-lhe agora vivenciar a perturbação, que lhe permitirá, mesmo que em acting-out, dirigir sua demanda a outro, ao Rei, de quem espera uma reparação, algo que atenue sua intensa angústia.

Lembremos que na angústia, tentamos evitar - nos diz Lacan algo que "se sustenta em vergonhosa certeza" (LACAN, 1997, p.84). 
Que certeza pode ser causa de vergonha para Tisbea, senão a de ter se deparado com algo que é da ordem do objeto do desejo? Algo, portanto, causa da angústia, pois, nos ensina Lacan, "a angústia não é sem objeto" (LACAN, 1997, p.141). Por isso, a saída de Tisbea em direção ao Rei, buscando uma reparação, é também uma saída no sentido de submeter-se à Lei. E a reparação buscada é a de manter-se como desejante, pois o desejo e a Lei são o mesmo, ambos impedem o acesso ao objeto.

Daquela aparição do fogo - um fogo prometido pelo próprio Don Juan - também ele terá de escapar, e isto ele o faz rapidamente.

$\mathrm{Na}$ verdade, toda a peça vai ganhando, ao longo do seu desenvolvimento, um acréscimo de velocidade em que, numa sutil aceleração do tempo, distâncias cada vez menores serão percorridas. Os fatos, de certa forma precipitam-se, e os atos, falham. A continuidade é cortada e, por essa descontinuidade, Don Juan tenta continuar sua corrida pela compacidade ${ }^{10}$ em busca d'A Mulher, Encore $^{11}$, ainda, buscando o gozo em corpo, En corps.

Continuemos então acompanhando o percurso de Don Juan, que se dará ao nível da emoção, do sintoma e da passagem ao ato, pois, diferenciando-se de Tisbea, ultrapassando-a ou sendo ultrapassado por ela, Don Juan não vivenciará com ela, nem muito menos como ela, a perturbação e o acting-out. Ele, sem dúvida, burlará a angústia.

Vamos encontrá-lo agora em Sevilla. Lá também se encontram seu pai - Don Diego Tenório, embaixador do rei -, Don Octavio e o Marquês de la Mota, antigo companheiro de farras de Don Juan. Para lá convergirão ainda as donzelas burladas. Todos esperam reparação pelos feitos de Don Juan.

9 LACAN, 1997, p.90.

10 O termo "compacidade" é utilizado por Lacan a partir das contribuições matemáticas do Teorema de Dedekind que trata da questão da continuidade e da descontinuidade operada pelo corte gerando um ponto de acumulação, isto é, fazendo surgir a compacidade. É como se, percorrendo a infinidade de pontos que surgem após o corte, Don Juan buscasse dar conta da infinidade de mulheres, tomando-as uma a uma.

11 Alusão ao título do Seminário 20 de Lacan: Encore, que se traduz em português por "ainda" e que pela homofonia nos remete também a En corps, "em corpo". 
Mas retrocedamos, novamente, um pouco:

O Rei - que é tio de Don Juan, bem como seu irmão, o pai de Don Juan - estando a par das intrigas criadas pelo sobrinho em Nápoles, decide fazer um intercâmbio de mulheres: ordena que Doña Ana, filha do Comendador Gonzalo de Ulloa, anteriormente destinada a Don Juan, case-se com Octavio, e que Isabela - antes destinada a Octavio - case-se com Don Juan. Além disto o Rei promove Don Juan a Conde, para que esteja à altura de Isabela.

Não é desprovida de significação esta medida adotada pelo Rei. Ela surge enquanto função do falo regulando o intercâmbio social, onde o sujeito se encontra alienado, reduzido, como diz Lacan, a "ser portador do falo" (LACAN, 1997, p.95). E antes da questão da interdição, Lacan nos remete ao que Levi-Strauss já havia demonstrado: à questão das preferências. ${ }^{12}$ Daí Lacan comentar, a propósito do intercâmbio de mulheres, que neste, o que vai preenchêlas é o falo. E complementa: "Não é preciso que se veja que é ele, o falo, que está em questão. Se se o vê, angustia." (Lacan,1997:328).

Assim inapreensível, Don Juan continua seu irremediável movimento. Porém, a partir de agora, ele que era quem sempre visitava, passa a ser visitado. De certa forma, é como se estivéssemos diante da outra versão do íncubo, o súcubo, ${ }^{13}$ pois Don Juan é surpreendido pela voz de uma mulher que só se deixa ver, não-toda, por uma fresta, e que lhe entrega uma carta, uma letra, destinada a outro.

Esta letra, sendo o que precipitará Don Juan por um caminho cada vez mais irreversível, é um convite de Doña Ana ao amante, o Marquês de la Mota, para que este a visite, uma vez que, por decisão do Rei, ela terá de casar-se com outro.

Don Juan comunica ao Marquês o conteúdo da carta, tendo antes o cuidado de modificar o pequeno detalhe da hora marcada para o encontro e mantém consigo a letra.

12 No Seminário 2, Lacan também aborda esta questão da preferência mostrando que seus elementos, mesmo estando velados, não deixam de ser essenciais (LACAN, 1995, p.328).

13 LACAN, 1997, p.70. 
Além disto, oferece-se para ajudar ao Marquês. em sua empreitada e, usando a capa deste vai ao encontro de Doña Ana, na hora do outro.

Os fatos se precipitam: Doña Ana desconfia que aquele não é seu amante e, antes mesmo que tenha se dado qualquer enlace carnal, grita como se sua honra houvesse sido tirada. Seu pai, o Comendador, vem seminu, em seu socorro; bate-se com Don Juan e se diz morto, por saber da perda da honra de sua filha, antes mesmo de ser mortalmente atingido por Don Juan.

Mais uma vez Don Juan foge. E apesar da dramaticidade dos fatos, não sente angústia, pois como diz Lacan, "a angústia é causa da dúvida" (LACAN, 1997, p.84), e ele não hesitará em partir ao encontro de novos enganos.

Devolve a capa que usou ao matar o Comendador a seu dono e na fuga se detém para participar de uma festa de casamento, onde, é claro, burlará os noivos.

Não sem razão, Batrício, o noivo, pressente como mau agouro a chegada de um fidalgo à sua festa, pois, Arminta a noiva, apesar de resistir ao assédio de Don Juan, acabará por ceder às suas promessas de casamento. Don Juan passa a ocupar então o lugar do noivo. A ela Don Juan também faz juras, mas, ao mesmo tempo, esconjura seu próprio fim:

Si acaso

la palabra y la fe mía

te faltare, ruego a Dios

que a traición y a alevosía

me dé muerte un hombre.

E à parte, comenta: "muerto, / que vivo Dios no permita." (MOLINA, 2000, p.313).

Vendo aproximar-se o momento em que Don Juan realizará sua passagem ao ato - o momento do movimento radical -, ocorre-me perguntar por que ele não tomou outro rumo, ou mesmo por que não continuou a enganar, a falsificar. Por que não continuou com o comportamento essencialmente significante? Por que, pergunto-me ainda, o Burlador de Sevilla não continuou a mentir como teria sido capaz de fazê-lo, por exemplo, até mesmo uma criança de dois anos 
que, como nos descreve Carlos Drummond, ${ }^{14}$ "é apenas um ser a quem a imaginação comanda, e que, com isso, dispõe de todos os filtros da poesia" (ANDRADE, 1989, p.150)?

Don Juan, sem dúvida, dispunha destes filtros, disto que seleciona a passagem de algo. Dispunha de amavios, os filtros amatórios produtores das beberagens que induzem ao amor. Dispunha de atrativos sedutores, encantos.

O filtro, seja da poesia - da metáfora, portanto -, seja da produção dos encantamentos do amor, retém um resto que, para aquele que bebe do filtrado, estará perdido.

No entanto, para Don Juan, o que poderia ter feito com que este filtro parasse de realizar sua função de filtração? O que poderia tê-lo obturado?

Recuemos ao único momento em que a antecipação de Don Juan falha, pois ele, como nos demonstra Lacan a respeito da histeria, "repete sempre o que há de inicial no seu trauma, isto é, um certo demasiado-cedo" (LACAN, 1989, p.80).

Recordemos a refinada série de antecipações que o autor nos apresenta: Don Juan modificando a hora marcada por Doña Ana, antecipa-se a seu amante, mas não consegue realizar seu intento uma vez que Doña Ana antecipa-se a ele, com seu grito de mulher desonrada. Em seguida, Don Gonzalo antecipa sua morte ao golpe fatal que será desferido por Don Juan.

Todas estas antecipações nos conduzem ao pressentimento sobre o qual Lacan chama a atenção, para que o ouçamos também como "o 'pré' do sentimento, o que está antes do nascimento de um sentimento"(LACAN, 1997, p.243).

Afinal o que é pré-sentido, senão que o filtro, apesar dos poros, apesar do orifício, retém algo? E o que é este algo retido?

Lacan, referindo-se à mulher enquanto aquela que detém a aparência de vaso para seu parceiro, diz que este parceiro "pensa que esse vaso pode conter o objeto de seu desejo" (LACAN, 1997, p.243).

14 A idéia de articular neste texto o comentário de Carlos Drummond surgiu como solução para um momento de impasse através da leitura do fragmento de texto intitulado "Netinho" de Fala, Amendoeira, realizada por meu filho Tiago, a quem especialmente agradeço. 
O que Don Juan encontra ao tentar desonrar Doña Ana, é uma mulher que já se diz desonrada. É o que Lacan afirma ser "a presença fantasmática do falo" (LACAN, 1997, p.:243): o falo de um outro homem, pré-enchendo o vaso.

Se esta associação é possível, o encontro de Don Juan com o fantasma de pedra do Comendador não poderá ser mais evitado, pois o filtro encontra-se, a partir de agora, obturado e, se persistirmos com a alusão ao vaso, pode-se dizer que este encontra-se transfigurado.

Esta transfiguração do vaso torna-o angustiante, pois o que vem encher este vaso é o objeto do desejo, constituído por intermédio do desejo do Outro.

Daí o inevitável primeiro encontro de Don Juan com o fantasma do Comendador, no qual o sujeito vai se encontrar em eclipse, fading:

!Valgame Dios! Todo el cuerpo

se ha bañado de un sudor

helado, y en las entrañas

se me ha helado el corazón (MOLINA, 2000, p.339).

Apesar disto, Don Juan não desiste de mostrar a Sevilla - ao Outro - seu valor, comprometendo-se a comparecer a um segundo encontro para cear com o fantasma, que no entanto põe em dúvida sua coragem, argumentando que ele, Don Juan, fugiu após tê-lo matado. A este argumento, Don Juan responde:

Huí de ser conocido, mas ya me tienes delante.

Di presto lo que quieres (MOLINA, 2000, p.358).

É a partir daqui que acaba para Don Juan a possibilidade de falsificar o traço, de se presentificar enquanto sujeito através desse traço "que quer se fazer tomar por um falso traço" (LACAN, 1997, p.72).

Don Juan, que antes supunha que o Outro não sabia, ou que não devia saber, agora supõe que o Outro sabe. Resta-lhe, portanto, interrogar: Che vuoi ? $^{15}$. Parte, pela última vez, em busca da revelação radical. E, se assim Don Juan o faz, é ainda na tentativa de mais uma

15 "Que queres?" Expressão usada por Lacan para marcar a questão posta pelo sujeito diante do desdobramento da fala, onde o desejo do sujeito é o desejo do Outro. 
vez agarrar-se a algo que falta ao Outro. Por aí, Don Juan espera reencontrar a hora da verdade.$^{16} \mathrm{E}$ a hora da verdade coincide com a hora marcada pelo Rei para o casamento dele com Isabela.

Acontece que Don Juan, portando-se como o objeto para o neurótico, chegará sempre antes ou depois da hora. Quando é lembrado por Catalinón que já se encontra atrasado para o casamento, responde: "Otro negocio tenemos que hacer, / aunque nos aguarden" (MOLINA, 2000, p.361). Irá, antes, à Igreja, cear com o morto.

Além disto, de tanto desejar agarrar ou agarrar-se ao resto retido pelo filtro, Don Juan não beberá do encantamento do amor. A ele, o morto servirá fel e vinagre.

Desta forma, chega Don Juan na hora da verdade para baterse, deparar-se com o engano, com a falsa demanda, pois ele será cobrado não pelo que fez, mas pela intenção...

...!ay! que me canso en vano

de tirar golpes al aire.

A tu hija no ofendí, que vio mis engaños antes.

...ao que o fantasma responde com desdém: "No importa, que ya pusiste / tu intento" (MOLINA, 2000, p.363).

Don Juan, cansando-se em vão de atingir o falo "porque o falo, mesmo real, é uma sombra" (LACAN, 1989, p.114), ainda tenta apelar para o significante: "Deja que llame / quien me confiese y absuelva” (MOLINA, 2000, p.363).

Porém, Don Juan encontra-se diante de seu destino. Diante do fantasma não encontra lugar, pois este lhe responde: "No hay lugar. Ya acuerdas tarde" (MOLINA, 2000, p.:363).

Já não pode mais escapar. Está condenado a permanecer no que é da esfera do sono, preso ao enigma, ao "significante opaco" (LACAN, 1997, p.70), ao mito. Terá o mesmo destino da Esfinge: ser consumido pelas chamas.

Aquele fogo, que antes era apenas um rastro, agora ergue-se na Igreja como enormes labaredas. E este fogo que se ergue no centro

16 LACAN, Jacques. Shakespeare, Duras, Wedeking, Joyce. 1989, p.79-80. 
do altar, bem como na lareira doméstica, é a deusa Héstia, ${ }^{17}$ a mesma a quem Zeus concedeu a permissão de manter-se eternamente virgem. Em sua direção, Don Juan caminhará, na tentativa de trans-fixar o que é da ordem do real. Passará: "Que me quemo, que me abraso. / Muerto soy" (MOLINA, 2000, p.363).

Ardendo para sempre nos sonhos de Héstia, Don Juan cai morto.

\section{REFERÊNCIAS BIBLIOGRÁFICAS}

ANDRADE, Carlos Drummond de. Frente e verso; fotobiografia de Carlos Drummond de Andrade. Rio de Janeiro: Edições Alumbramento, 1989.

BRANDÃO, Junito de Souza. Mitologia grega. Petrópolis: Vozes, 1993.

FREUD, Sigmund. Obras completas de Sigmund Freud. Madrid: Ed. Biblioteca Nueva, 1981.

HUET, Robert. A angústia: reflexões. Recife: Centro de Estudos Freudianos do Recife, 1999.

LACAN, Jacques. O seminário, livro 20: mais, ainda. 1972-1973. Rio de Janeiro: Jorge Zahar Editor, 1985.

LACAN, Jacques. Shakespeare, Duras, Wedeking, Joyce. Lisboa: Assírio \& Alvim, 1989.

LACAN, Jacques. O seminário, livro 2: o eu na teoria de Freud e na técnica da psicanálise 1954-1955. Rio de Janeiro: Jorge Zahar Editor, 1995.

LACAN, Jacques. A angústia, seminário 1962-1963.Publicação para circulação interna do CEF de Recife. Recife: s/e, 1997.

LISBOA, Luiz Carlos. Pequeno guia da literatura universal. São Paulo: Círculo do Livro, s/d.

MOLINA, Tirso de (obra atribuída). El burlador de Sevilla o el convidado de piedra. Madrid: Ediciones Cátedra, 2000.

17 BRANDÃO, 1993, p.275-276. 